\title{
Synthesis of Circumpyrene by Alkyne Benzannulation of Brominated Dibenzo[hi,st]ovalene
}

pubs.acs.org/JACS

\author{
Qiang Chen, ${ }^{\dagger \odot}$ Dieter Schollmeyer, ${ }^{\dagger}$ Klaus Müllen, ${ }^{*},+, \odot$ and Akimitsu Narita ${ }^{*},+\| \odot$ \\ ${ }^{\dagger}$ Max Planck Institute for Polymer Research, Ackermannweg 10, 55128, Mainz, Germany \\ ${ }^{\ddagger}$ Institut für Organische Chemie, Johannes Gutenberg-Universität Mainz, Duesbergweg 10-14, 55099 Mainz, Germany \\ ${ }^{\S}$ Institute of Physical Chemistry, Johannes Gutenberg-Universität Mainz, Duesbergweg 10-14, 55128 Mainz, Germany \\ "Organic and Carbon Nanomaterials Unit, Okinawa Institute of Science and Technology Graduate University, 1919-1 Tancha, \\ Onna-son, Kunigami, Okinawa 904-0495, Japan
}

\section{Supporting Information}

ABSTRACT: A transition-metal catalyzed alkyne benzannulation allowed an unprecedented synthesis of circumpyrene, starting from 3,11-dibromo-6,14-dimesityldibenzo[hi,st] ovalene (DBOV). The circumpyrene was characterized by a combination of NMR, mass spectrometry, and single-crystal X-ray diffraction analysis, revealing its multizigzag-edged structure. Two newly introduced $\mathrm{C}=\mathrm{C}$ bonds in circumpyrene strongly perturbed the electronic structures of DBOV, as evidenced by increased optical and electrochemical energy gaps. This is in good agreement with an increased number of Clar's sextets as well as a decreased number of $\pi$-electrons in the conjugation pathway of circumpyrene, according to anisotropy of the induced current density (ACID) calculations. The present approach opens a new avenue to multizigzag-edged nanographenes and offers insights into their (opto)electronic properties.

$\mathrm{N}$ anographenes, extended, nanosized, polycyclic aromatic hydrocarbons (PAHs), exhibit unique and structuredependent electronic, optical, and magnetic properties, ${ }^{1-3}$ highlighting their potential as next-generation carbon materials for photonics, (opto)electronics, and spintronics. ${ }^{4-10}$ Nanographenes having both zigzag edges (L-regions) and armchair edges (with bay-regions), e.g. periacenes, anthenes, and zethrenes, have attracted particular attention because of their low energy gaps and/or open-shell characters. ${ }^{11-18}$ On the other hand, multizigzag-edged nanographenes, consisting only of zigzag edges and K-regions, without bay regions, have also been frequent targets of theoretical studies. ${ }^{19-28}$ Nevertheless, there are still a limited number of synthesized examples, precluding detailed experimental investigations. ${ }^{29}$ Circumarenes are a subclass of such nanographenes featuring a central aromatic core surrounded by one outer layer of annulene (Scheme 1). The smallest circumarenes, namely circumbenzene (coronene $)^{30-34}$ and circumnaphthalene (ovalene), ${ }^{35}$ were synthesized by Scholl and Clar, respectively, and their soluble derivatives were later employed in supramolecular self-assembly and (opto)electronic device studies. ${ }^{36-38}$ A larger circumanthracene was first synthesized by Diederich and colleagues, ${ }^{39}$ and its tetracyano derivative was more recently reported by Feng
Scheme 1. Structures of Representative Circumarenes

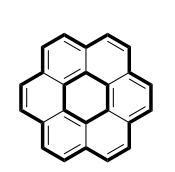

Circumbenzene (Coronene) Scholl / $1932^{22}$

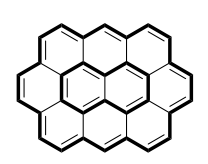

Circumnaphthalene (Ovalene) Clar / $1948^{23}$

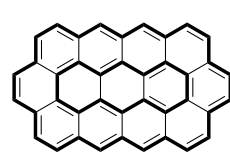

Circumanthracene Diederich / $1991^{27}$ Feng \& Liu / $2018^{13}$

et al. ${ }^{12}$ Circumpyrene and circumcoronene, as the next members of the circumarene family, have been targets of theoretical studies. ${ }^{19,24-28}$ However, to the best of our knowledge, synthesis of circumarenes comprising a central aromatic unit larger than three benzene rings has never been achieved.

The challenge has been that multizigzag-edged nanographenes cannot be readily obtained by the cyclodehydrogenation of preformed polyphenylene precursors, which has been well established and has yielded numerous PAHs in recent decades. ${ }^{40}$ Reactions occurring at bay regions of PAHs, such as intramolecular Friedel-Crafts alkylation, ${ }^{41-43}$ Diels-Alder cycloaddition, $^{30,35}$ and cyclization of preinstalled ethynyl bonds, ${ }^{36}$ permit this obstacle to be surmounted and are capable of building extended aromatic cores. In addition, Pd-catalyzed direct annulation of substituted acetylenes and halogenated PAHs has been used to form new fused ring systems with extra five-, six-, or eight-membered rings appended. ${ }^{44-47}$ Recently, we reported syntheses of dibenzo[hi,st] ovalene (DBOV) derivatives, including 1 (Scheme 2), as new nanographenes with both zigzag and armchair edges. ${ }^{43,48-50}$ Anticipating that introduction of two additional double bonds to the bay regions of DBOV would lead to the long-awaited circumpyrene, we explored possible synthetic strategies.

Herein, we describe a concise synthesis of two circumpyrene derivatives $\mathbf{5} \mathbf{a}$ and $\mathbf{5 b}$ using platinum- and palladium-catalyzed cyclization and benzannulation reactions, respectively, as the key steps, starting from DBOV derivatives. Although possessing multiple zigzag edges, these molecules exhibit remarkably high stability under ambient conditions. Spectroscopic and electrochemical characterizations reveal significant electronic effects of

Received: October 11, 2019

Published: December 9, 2019 
Scheme 2. Synthesis of Circumpyrenes via Transition-Metal Catalyzed Benzannulation ${ }^{a}$

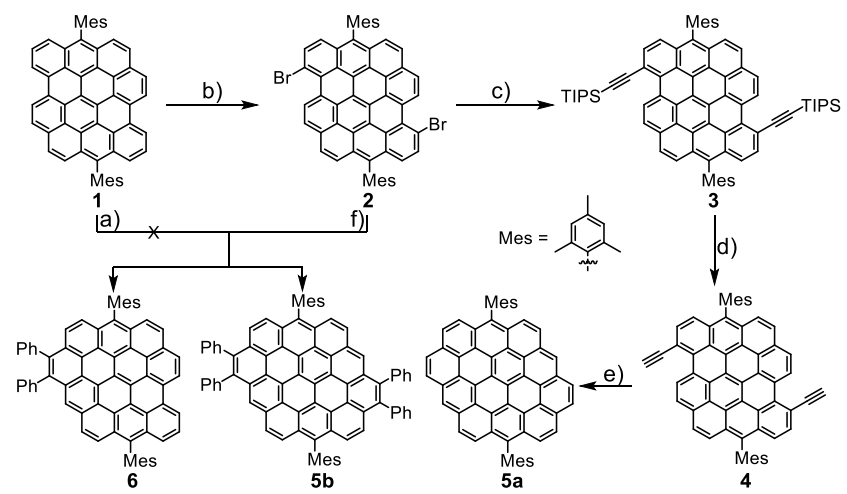

${ }^{a}$ Reagents and conditions: (a) diphenylacetylene, $o$-dichlorobenzene, $180{ }^{\circ} \mathrm{C}, 24 \mathrm{~h}$, no reaction; (b) NBS, THF, rt, 79\% yield; (c) TIPSacetylene, $\mathrm{Pd}\left(\mathrm{PPh}_{3}\right)_{2} \mathrm{Cl}_{2} \cdot \mathrm{CH}_{2} \mathrm{Cl}_{2}$, CuI, TEA, THF, $80{ }^{\circ} \mathrm{C}$, overnight, $31 \%$ yield; (d) TBAF, THF, rt, $32 \%$ yield; (e) $\mathrm{PtCl}_{2}$, toluene, $80{ }^{\circ} \mathrm{C}$, $24 \mathrm{~h}, 46 \%$ yield; (f) diphenyl acetylene, $\mathrm{Pd}(\mathrm{OAc})_{2}, \mathrm{NaOAc}, \mathrm{LiCl}$, DMF, $130{ }^{\circ} \mathrm{C}, 12 \mathrm{~h}$, for $\mathbf{6 :} 40 \%$ yield; for $\mathbf{5 b}$ : $15 \%$ yield. THF: tetrahydrofuran. DMF: $N, N$-dimethylformamide. TEA: triethylamine.

the fused $\mathrm{C}=\mathrm{C}$ bonds when going from $\mathrm{DBOV}$ to circumpyrene.

Toward the synthesis of circumpyrene $\mathbf{5 b}$, we initially attempted direct Diels-Alder cycloaddition of $\mathbf{1}$ with diphenylacetylene (Scheme 2). However, no reaction occurred even when heated at $180^{\circ} \mathrm{C}$ in $o$-dichlorobenzene for $24 \mathrm{~h}$, most probably because of the weakly pronounced diene character of $1 .^{51}$ In an alternative approach, 3,11-dibromo-6,14-dimesityldibenzo[hi,st] ovalene (2) was considered as a precursor that could be obtained by regioselective bromination of 1 with $\mathrm{N}$ bromosuccinimide (NBS). ${ }^{49}$ We previously reported a Sonogashira coupling of $\mathbf{2}$ with triisopropylsilyl (TIPS) acetylene to obtain 3 in $31 \%$ yield. ${ }^{49}$ Deprotection of 3 with tetra- $n$ butylammonium fluoride (TBAF) proceeded at room temperature to give 4 in $32 \%$ yield. Subsequently, $\mathrm{PtCl}_{2}$ catalyzed cyclization of the ethynyl groups yielded circumpyrene $\mathbf{5 a}$ in $46 \%$ yield. 5a could be characterized by ${ }^{1} \mathrm{H}$ NMR and highresolution mass spectrometry (see SI), but its low solubility hampered further characterizations, for example, by ${ }^{13} \mathrm{C}$ NMR and cyclic voltammetry. In order to increase the solubility of the circumpyrene and also to simplify its synthesis, we considered direct benzannulation of 2 with diarylacetylenes. ${ }^{44}$ To our delight, reaction of $\mathbf{2}$ and diphenylacetylene in toluene at $130{ }^{\circ} \mathrm{C}$ using $\mathrm{Pd}\left(\mathrm{PPh}_{3}\right)_{4}$ as catalyst provided a mixture of $\mathbf{6}$ and $\mathbf{5 b}$ as one- and twofold benzannulated products (Figure S1). After optimizing the reaction conditions, the combination of Pd(OAc) $)_{2} / \mathrm{NaOAc} / \mathrm{LiCl}$ achieved the best result, affording 6 and $\mathbf{5 b}$ in $40 \%$ and $15 \%$ yield, respectively.

${ }^{1} \mathrm{H}$ NMR spectra (Figure 1) of $\mathbf{1}, \mathbf{6}$, and $\mathbf{5 b}$ displayed wellresolved peaks that could be fully assigned by two-dimensional (2D) NMR techniques (Figures S11-S12 and S16-S17). After fusing one $\mathrm{C}=\mathrm{C}$ bond to 1 , five more new peaks appeared in the ${ }^{1} \mathrm{H}$ NMR spectrum of $\mathbf{6}$. In contrast, circumpyrene $\mathbf{5 b}$ exhibited only one singlet peak and four sets of doublet peaks, in accordance with its $C_{2 h}$ symmetry. Compared with 1 , the signals of protons in the core of $\mathbf{5 b}$ are shifted downfield as a result of the extended size of its aromatic core and more significant deshielding. For example, the doublet peak of 1 at $8.61 \mathrm{ppm}$ $\left(\mathrm{H}^{1}\right)$ was moved to $9.27 \mathrm{ppm}$ in the spectrum of 6 and $9.95 \mathrm{ppm}$ in that of circumpyrene $\mathbf{5 b}$. Other peaks also displayed similar

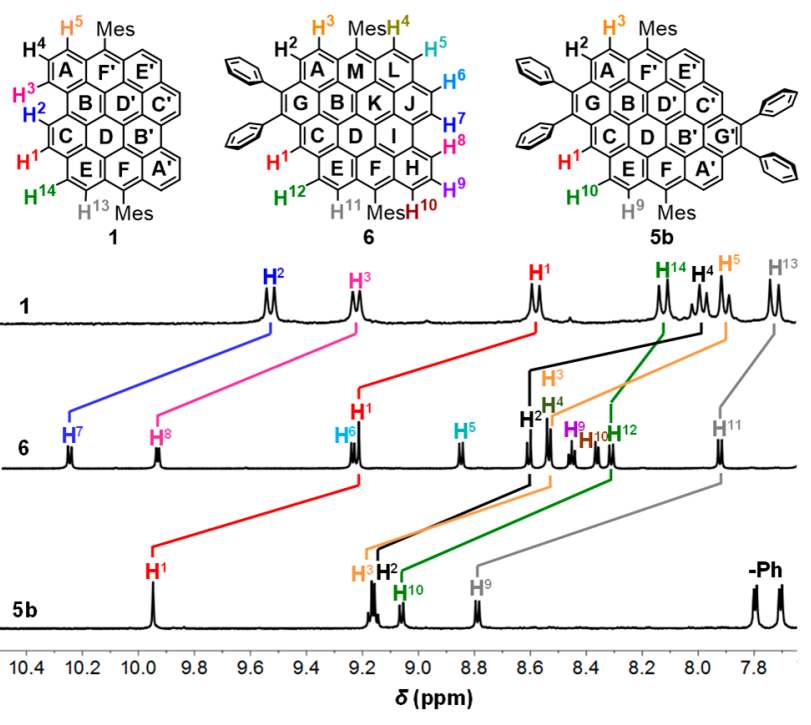

Figure 1. ${ }^{1} \mathrm{H}$ NMR spectra of $\mathbf{1}(300 \mathrm{MHz}, 298 \mathrm{~K}), \mathbf{6}$, and $\mathbf{5 b}$ in tetrahydrofuran- $d_{8}: \mathrm{CS}_{2}(1: 1)(700 \mathrm{MHz}, 298 \mathrm{~K})$.

low-field shifts. The potential open-shell character of circumpyrene could be excluded by these sharp ${ }^{1} \mathrm{H}$ NMR peaks observed at room temperature and by its high chemical stability in air. Further insights into the aromaticity of the circumpyrene skeleton came from a nucleus-independent chemical shift (NICS) analysis (Figure $2 \mathrm{a}-2 \mathrm{c}):^{52,53}$ Going from 1 to $\mathbf{6}$ and $\mathbf{5 b}$, NICS (1) values of all benzene rings decrease while the newly formed benzene rings $\mathrm{G} / G^{\prime}$ have the second highest aromaticity. Moreover, the antiaromatic rings $\mathrm{B} / \mathrm{B}^{\prime}$ in $\mathbf{1}$ (Figure $2 \mathrm{a}$ ) become a)

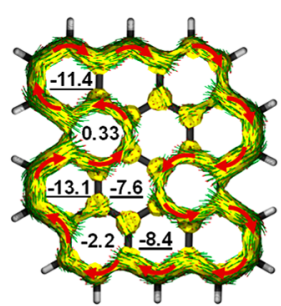

c)

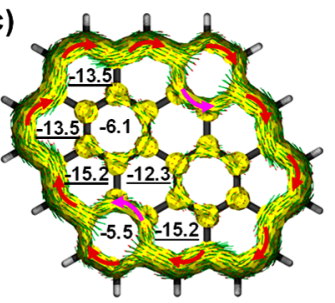

e)

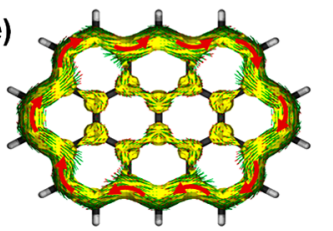

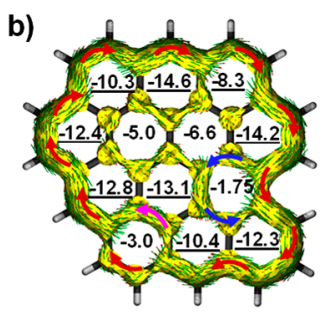

d)
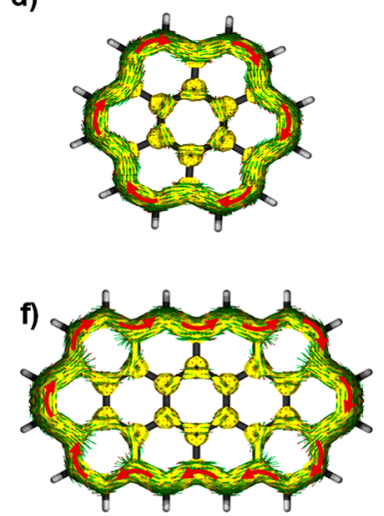

Figure 2. Calculated ACID (B3LYP/6-31G(d,p)) plots of (a) 1, (b) 6, (c) $5 b$, (d) coronene, (e) ovalene, and (f) circumanthracene (isovalue $=0.05$ ). Only contributions from $\pi$-electrons of the aromatic cores are considered. The magnetic field vector is perpendicular to the ring plane and points outward. Red arrows indicate directions of induced ring current. For $(a)-(c)$, the numbers inside the six-membered rings indicate NICS (1) values calculated at the same level (substituents were replaced by $\mathrm{H}$ for all calculations). 
aromatic in $\mathbf{5 b}$. These results accord with experimentally observed chemical shifts of $\mathrm{H}^{1}, \mathrm{H}^{2}$, and $\mathrm{H}^{3}$ at lower fields when compared with $\mathrm{H}^{9}$ and $\mathrm{H}^{10}$ for $\mathbf{5 b}$.

The anisotropy of the induced current density (ACID) $)^{54}$ plot of DBOV calculated at B3LYP/6-31G $(\mathrm{d}, \mathrm{p})$ level (Figure 2a) indicates that at the isosurface value 0.05 there is clockwise (diatropic) ring current delocalized over a pathway comprising $34 \pi$-electrons. After fusing with one $\mathrm{C}=\mathrm{C}$ bond, $\pi$-electrons involved in the conjugation pathway decrease to 30 (Figure $2 \mathrm{~b}$ ). In circumpyrene, only $26 \pi$-electrons in the outer rim participate in the diatropic ring current, and the two benzene rings in the center possess almost no induced ring current (Figure 2c). These results are in very good agreement with the low aromaticity of the $\mathrm{B} / \mathrm{B}^{\prime}$ and $\mathrm{E} / \mathrm{E}^{\prime}$ rings, and also resemble characteristics of the ACID calculated for smaller circumarenes (Figure 2d-2f).

The single-crystal structure of $\mathbf{5 b}$ clearly revealed the central pyrene and zigzag-shaped periphery forming the outer rim (Figure $3 a-b)$. The main skeleton of $\mathbf{5 b}$ adopts a planar

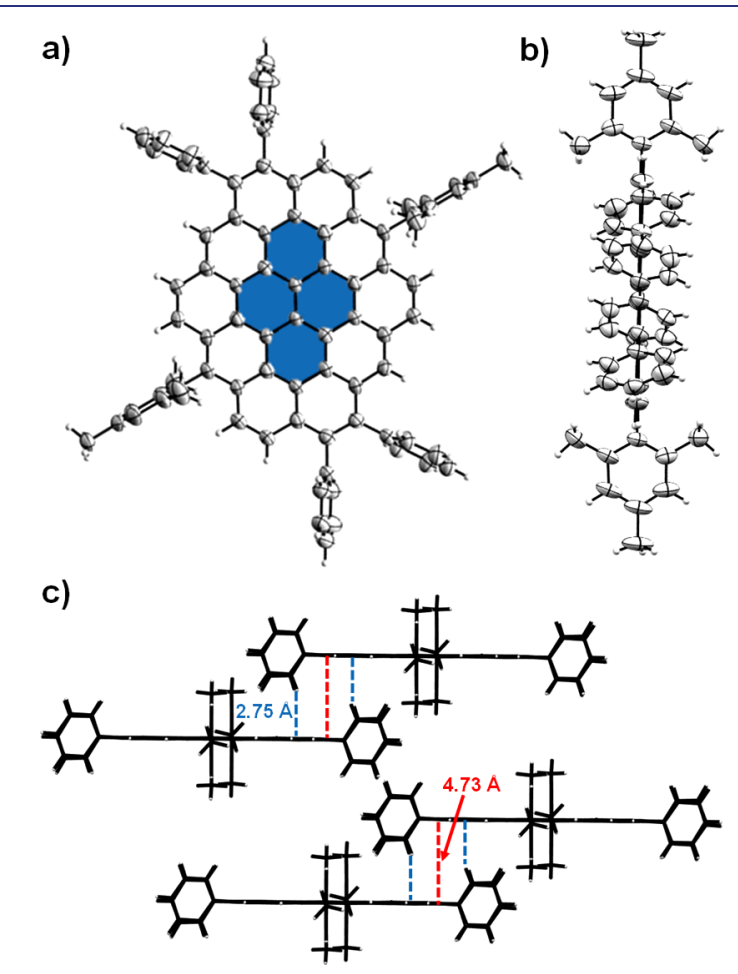

Figure 3. Single-crystal structure of circumpyrene $\mathbf{5 b}$, (a) front view, (b) side view ( $\mathrm{H}, \mathrm{C}$ atoms are shown as ellipsoids set at $50 \%$ probability); (c) packing arrangement of $\mathbf{5 b}$ in the crystal (solvents are omitted for clarity).

configuration, with all peripheral substituents being nearly perpendicular to the core (dihedral angels $85^{\circ}-90^{\circ}$ ). Two circumpyrene molecules are stacked almost parallel to each other to form a dimer, which are staggered with respect to each other (Figure 3c and Figure S2). The plane-to-plane distance is $4.73 \AA$, denoting an absence of $\pi-\pi$ interactions between circumpyrene molecules. On the other hand, the distance between the $\mathrm{CH}$ bonds of the phenyl rings and the core of the neighboring circumpyrene molecules is as short as $2.75 \AA$ (less than the sum of the van der Waals radius), indicating the existence of $\mathrm{CH}-\pi$ interactions, ${ }^{55}$ which is responsible for the close intermolecular packing in the single-crystal structure.
The UV-vis absorption and fluorescence spectra of 1, 6, 5a, and $\mathbf{5 b}$ were measured in toluene to reveal the effect of benzannulation on their optoelectronic properties (Figure $4 a$
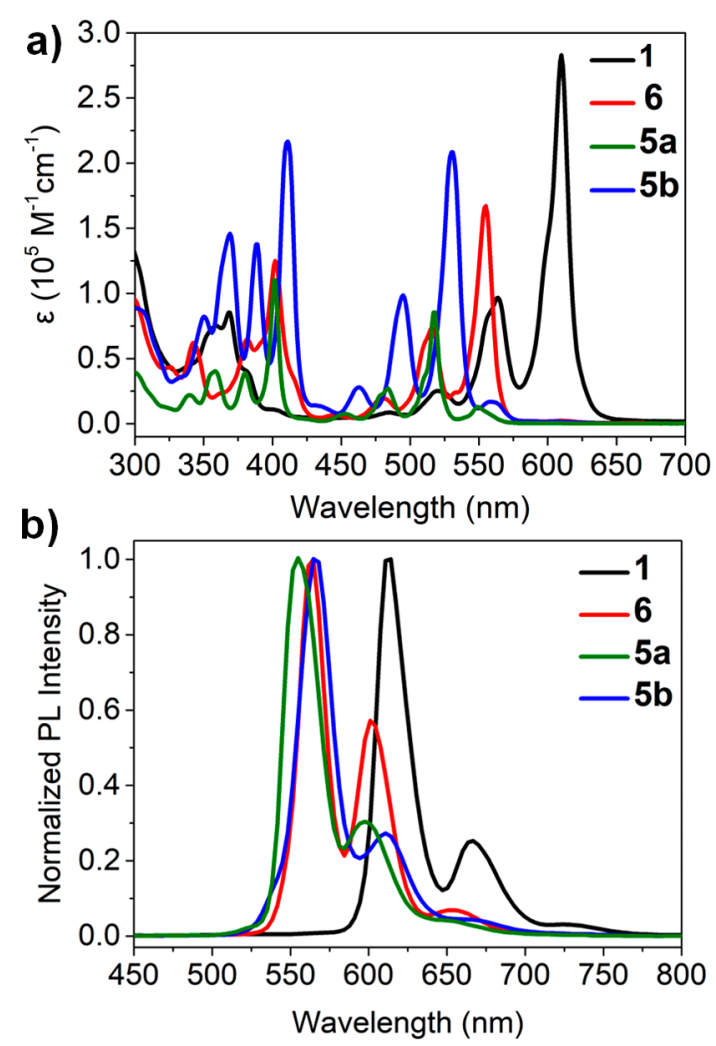

Figure 4. (a) UV-vis absorption and (b) fluorescence spectra of 1, 6, and $\mathbf{5 a} / \mathbf{5 b}$ in toluene with concentration of $10^{-6} \mathrm{M}$.

and Figure S3). Fusion of one double bond to the bay region of 1 induced significant blue shifts of the longest absorption wavelength $\left(\lambda_{\max }\right)$ from $611 \mathrm{~nm}(1)$ to $555 \mathrm{~nm}(6)$, indicating an increase in the highest occupied molecular orbital (HOMO)-lowest unoccupied molecular orbital (LUMO) gap, although the aromatic core size was extended. This observation is consistent with the decreased number of $\pi$ electrons in the conjugation pathway of 6 in the ACID plots (Figure $2 \mathrm{a}$ and $\mathrm{b}$ ), as well as an increased number of Clar's $\pi$ sextet from four to five (Scheme S1). ${ }^{56}$ Circumpyrenes 5a and $\mathbf{5 b}$ displayed different patterns of UV-vis absorption from those of 1 and 6, and their longest-wavelength bands located at 549 and $558 \mathrm{~nm}$, respectively, were apparently a forbidden transition. The intensity ratios of these peaks were independent of the concentration of $5\left(10^{-5}-10^{-8} \mathrm{M}\right)$, which excluded the possibility of aggregation-induced effects (Figure S4). Notably, these observations agreed very well with a recent report by Lischka and co-workers, who theoretically predicted forbidden $\mathrm{HOMO}-1(\mathrm{H}-1) \rightarrow$ LUMO $(\mathrm{L})$ and $\mathrm{H} \rightarrow \mathrm{L}+1$ transitions as the longest-wavelength absorption of circumpyrene, based on density functional theory/multireference configuration interaction (DFT/MRCI) calculations. ${ }^{27}$ On the other hand, the second-longest-wavelength band of $\mathbf{5}$ was mainly assigned to $\mathrm{H}$ $\rightarrow$ L transitions (Figure S5, Table S1), ${ }^{27}$ which are split into several small shoulder peaks due to vibronic coupling. The latter corresponded to the longest-wavelength bands of 1 and 6 . There was no detectable change in the absorption spectra of 5 after storage of the solution under ambient conditions for more than 8 
months, demonstrating its extremely high stability. In fluorescence spectra (Figure 4b), the maximum emission wavelengths of $1,6,5 a$, and 5 b were located at $614,563,555$, and $566 \mathrm{~nm}$, respectively, and their absolute fluorescence quantum yields $(\Phi)$ decreased dramatically after fusing extra double bonds from 0.79 to $0.42,0.11$, and 0.17 . Stokes shifts were less than $10 \mathrm{~nm}$ (Figure S3), indicating the structural rigidity of these molecules.

Cyclic voltammetry (CV) analysis of 1 revealed two sets of reversible reduction and oxidation peaks with the half-wave potential of the first oxidation and reduction peaks as -0.01 and $-1.67 \mathrm{~V}$ relative to $\mathrm{Fc} / \mathrm{Fc}^{+}$(Figure 5a). Fusion with one double

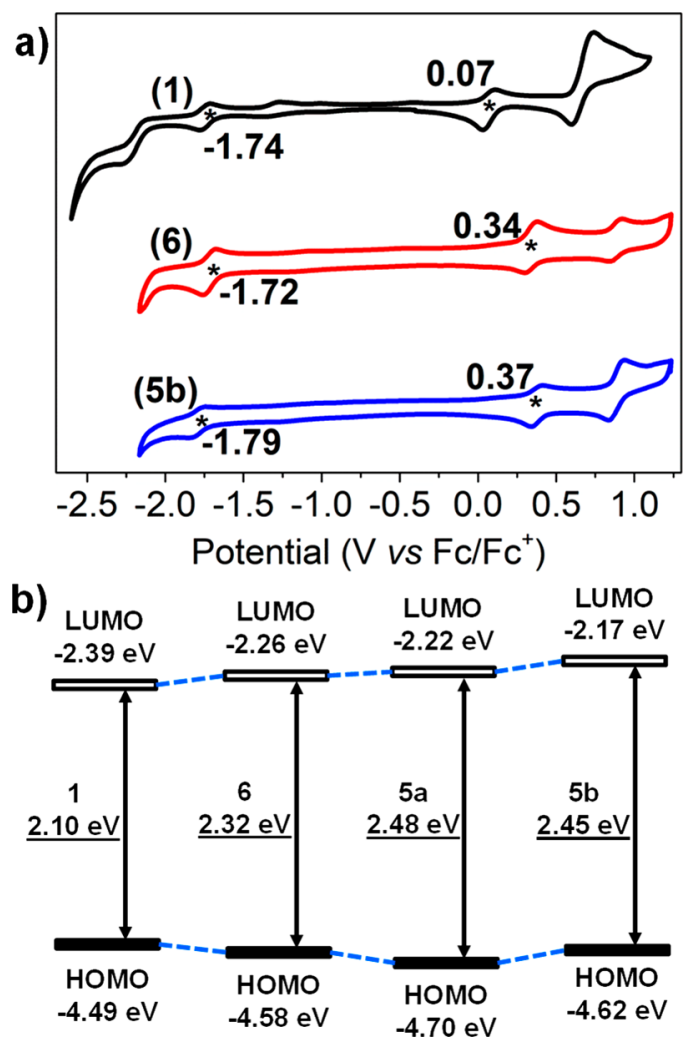

Figure 5. (a) Cyclic voltammograms of $\mathbf{1}, \mathbf{6}$, and $\mathbf{5 b}$ measured in $0.1 \mathrm{M}$ tetra- $n$-butylammonium hexafluorophosphate in dichloromethane $(*$ indicates the onset potential of these oxidation/reduction peaks). (b) HOMO, LUMO, and energy gaps of $\mathbf{1 - 5 b}$ calculated by DFT at the B3LYP/6-31G(d,p) level.

bond to form 6 had a negligible effect on the reduction potential of $\mathbf{1}$, but greatly increased its first oxidation potential. $\mathbf{5 b}$ exhibited the first oxidation potential at $0.31 \mathrm{~V}$ and slightly lowered the first reduction potential at $-1.71 \mathrm{~V}$. The electrochemical energy gaps were estimated from the onsets of the first oxidation and reduction potential to be 1.81, 2.06, and $2.16 \mathrm{eV}$, for $\mathbf{1}, \mathbf{6}$, and $\mathbf{5 b}$, respectively. This trend agreed with the HOMO-LUMO gaps based on the DFT calculations (Figure $5 \mathrm{~b}$ and $\mathrm{S} 6$ ) and could be reasonably explained by the decreased number of $\pi$-electrons in the conjugation pathway after fusing with $\mathrm{C}=\mathrm{C}$ bonds, according to the ACID plots (Figure 2).

In conclusion, we have achieved the synthesis of circumpyrenes as novel, multizigzag-edged nanographenes, based on (1) transition-metal catalyzed cyclization of ethynyl-substituted DBOV and (2) direct benzannulation of dibrominated DBOV with diphenylacetylene. Stepwise fusion of extra benzene rings to the bay region of DBOV enlarged their energy gaps, which was demonstrated by UV-vis absorption spectroscopy and CV measurements, and was supported with theoretical calculations. Circumpyrene represents the largest circumarene molecule synthesized thus far and provides further insights into this intriguing class of PAHs, not only the optoelectronic and electrochemical properties, as studied here, but also more detailed photophysics, self-assembly behavior, and potential applications in electronic devices as the next steps. Moreover, the current synthetic approach for circumpyrenes should enable synthesis of a greater variety of unprecedented nanographenes with multiple zigzag edges.

\section{ASSOCIATED CONTENT}

S Supporting Information

The Supporting Information is available free of charge at https://pubs.acs.org/doi/10.1021/jacs.9b10957.

Experimental details, synthesis, X-ray crystallography details, HR mass spectra, NMR spectra and computational studies (PDF)

Data for $\mathbf{5 b}$ (CIF)

\section{AUTHOR INFORMATION}

\section{Corresponding Authors}

*narita@mpip-mainz.mpg.de

*muellen@mpip-mainz.mpg.de

ORCID

Qiang Chen: 0000-0001-5612-1504

Klaus Müllen: 0000-0001-6630-8786

Akimitsu Narita: 0000-0002-3625-522X

Notes

The authors declare no competing financial interest.

\section{ACKNOWLEDGMENTS}

This work was financially supported by the Max Planck Society.

\section{REFERENCES}

(1) Narita, A.; Wang, X. Y.; Feng, X.; Müllen, K. New advances in nanographene chemistry. Chem. Soc. Rev. 2015, 44, 6616-6643.

(2) Ponomarenko, L. A.; Schedin, F.; Katsnelson, M. I.; Yang, R.; Hill, E. W.; Novoselov, K. S.; Geim, A. K. Chaotic Dirac billiard in graphene quantum dots. Science 2008, 320, 356-358.

(3) Zhao, S.; Lavie, J.; Rondin, L.; Orcin-Chaix, L.; Diederichs, C.; Roussignol, P.; Chassagneux, Y.; Voisin, C.; Müllen, K.; Narita, A.; Campidelli, S.; Lauret, J. S. Single photon emission from graphene quantum dots at room temperature. Nat. Commun. 2018, 9, 3470.

(4) Kim, S.; Kim, B.; Lee, J.; Shin, H.; Park, Y.-I.; Park, J. Design of fluorescent blue light-emitting materials based on analyses of chemical structures and their effects. Mater. Sci. Eng., R 2016, 99, 1-22.

(5) Laschat, S.; Baro, A.; Steinke, N.; Giesselmann, F.; Hagele, C.; Scalia, G.; Judele, R.; Kapatsina, E.; Sauer, S.; Schreivogel, A.; Tosoni, M. Discotic liquid crystals: from tailor-made synthesis to plastic electronics. Angew. Chem., Int. Ed. 2007, 46, 4832-4887.

(6) Mei, J.; Diao, Y.; Appleton, A. L.; Fang, L.; Bao, Z. Integrated materials design of organic semiconductors for field-effect transistors. J. Am. Chem. Soc. 2013, 135, 6724-6746.

(7) Pisula, W.; Feng, X.; Müllen, K. Tuning the columnar organization of discotic polycyclic aromatic hydrocarbons. Adv. Mater. 2010, 22, 3634-3649.

(8) Sergeyev, S.; Pisula, W.; Geerts, Y. H. Discotic liquid crystals: a new generation of organic semiconductors. Chem. Soc. Rev. 2007, 36, $1902-1929$. 
(9) Wohrle, T.; Wurzbach, I.; Kirres, J.; Kostidou, A.; Kapernaum, N.; Litterscheidt, J.; Haenle, J. C.; Staffeld, P.; Baro, A.; Giesselmann, F.; Laschat, S. Discotic Liquid Crystals. Chem. Rev. 2016, 116, 1139-1241.

(10) Wu, J.; Pisula, W.; Müllen, K. Graphenes as potential material for electronics. Chem. Rev. 2007, 107, 718-747.

(11) Inoue, J.; Fukui, K.; Kubo, T.; Nakazawa, S.; Sato, K.; Shiomi, D.; Morita, Y.; Yamamoto, K.; Takui, T.; Nakasuji, K. The First Detection of a Clar's Hydrocarbon, 2,6,10-Tri-tert-Butyltriangulene: A GroundState Triplet of Non-Kekulé Polynuclear Benzenoid Hydrocarbon. J. Am. Chem. Soc. 2001, 123, 12702-12703.

(12) Ajayakumar, M. R.; Fu, Y.; Ma, J.; Hennersdorf, F.; Komber, H.; Weigand, J. J.; Alfonsov, A.; Popov, A. A.; Berger, R.; Liu, J.; Müllen, K.; Feng, X. Toward Full Zigzag-Edged Nanographenes: peri-Tetracene and Its Corresponding Circumanthracene. J. Am. Chem. Soc. 2018, 140, 6240-6244.

(13) Ni, Y.; Gopalakrishna, T. Y.; Phan, H.; Herng, T. S.; Wu, S.; Han, Y.; Ding, J.; Wu, J. A Peri-tetracene Diradicaloid: Synthesis and Properties. Angew. Chem., Int. Ed. 2018, 57, 9697-9701.

(14) Liu, J.; Ravat, P.; Wagner, M.; Baumgarten, M.; Feng, X.; Müllen, $\mathrm{K}$. Tetrabenzo[a, $\mathrm{f}, \mathrm{j}, \mathrm{o}]$ perylene: a polycyclic aromatic hydrocarbon with an open-shell singlet biradical ground state. Angew. Chem., Int. Ed. 2015, 54, 12442-12446.

(15) Konishi, A.; Hirao, Y.; Nakano, M.; Shimizu, A.; Botek, E.; Champagne, B.; Shiomi, D.; Sato, K.; Takui, T.; Matsumoto, K.; Kurata, H.; Kubo, T. Synthesis and characterization of teranthene: a singlet biradical polycyclic aromatic hydrocarbon having Kekule structures. J. Am. Chem. Soc. 2010, 132, 11021-11023.

(16) Konishi, A.; Hirao, Y.; Matsumoto, K.; Kurata, H.; Kishi, R.; Shigeta, Y.; Nakano, M.; Tokunaga, K.; Kamada, K.; Kubo, T. Synthesis and characterization of quarteranthene: elucidating the characteristics of the edge state of graphene nanoribbons at the molecular level. J. Am. Chem. Soc. 2013, 135, 1430-1437.

(17) Sun, Z.; Zeng, Z.; Wu, J. Zethrenes, extended p-quinodimethanes, and periacenes with a singlet biradical ground state. Acc. Chem. Res. 2014, 47, 2582-2591.

(18) Umeda, R.; Hibi, D.; Miki, K.; Tobe, Y. Tetradehydrodinaphtho[10]annulene: A Hitherto Unknown Dehydroannulene and a Viable Precursor to Stable Zethrene Derivatives. Org. Lett. 2009, 11, 41044106.

(19) Philpott, M. R.; Kawazoe, Y. Transition metal sandwich molecules with large $(C n, n \geqslant 24)$ zigzag poly aromatic hydrocarbons. Chem. Phys. 2008, 348, 69-82.

(20) Agapito, L. A.; Kioussis, N.; Kaxiras, E. Electric-field control of magnetism in graphene quantum dots: Ab initio calculations. Phys. Rev. B: Condens. Matter Mater. Phys. 2010, 82, 201411.

(21) Pelloni, S.; Lazzeretti, P. Polygonal current models for polycyclic aromatic hydrocarbons and graphene sheets of various shapes. $J$. Comput. Chem. 2018, 39, 21-34.

(22) Trinquier, G.; Malrieu, J. P. Predicting the Open-Shell Character of Polycyclic Hydrocarbons in Terms of Clar Sextets. J. Phys. Chem. A 2018, 122, 1088-1103.

(23) Yumura, T.; Kimura, K.; Kobayashi, H.; Tanaka, R.; Okumura, N.; Yamabe, T. The use of nanometer-sized hydrographene species for support material for fuel cell electrode catalysts: a theoretical proposal. Phys. Chem. Chem. Phys. 2009, 11, 8275-8284.

(24) Weisman, J. L.; Lee, T. J.; Salama, F.; Head-Gordon, M. Timedependent Density Functional Theory Calculations of Large Compact Polycyclic Aromatic Hydrocarbon Cations: Implications for the Diffuse Interstellar Bands. Astrophys. J. 2003, 587, 256-261.

(25) Philpott, M. R.; Kawazoe, Y. Metal Sandwich Molecules: Planar Metal Atom Arrays between Aromatic Hydrocarbons. Mater. Trans. 2007, 48, 693-699.

(26) Soncini, A.; Steiner, E.; Fowler, P. W.; Havenith, R. W. A.; Jenneskens, L. W. Perimeter Effects on Ring Currents in Polycyclic Aromatic Hydrocarbons: Circumcoronene and Two Hexabenzocoronenes. Chem. - Eur. J. 2003, 9, 2974-2981.

(27) Shi, B.; Nachtigallova, D.; Aquino, A. J. A.; Machado, F. B. C.; Lischka, $\mathrm{H}$. High-level theoretical benchmark investigations of the UVvis absorption spectra of paradigmatic polycyclic aromatic hydro- carbons as models for graphene quantum dots. J. Chem. Phys. 2019, 150, 124302 .

(28) Menon, A.; Dreyer, J. A. H.; Martin, J. W.; Akroyd, J.; Robertson, J.; Kraft, M. Optical band gap of cross-linked, curved, and radical polyaromatic hydrocarbons. Phys. Chem. Chem. Phys. 2019, 21, 1624016251.

(29) Gu, Y.; Wu, X.; Gopalakrishna, T. Y.; Phan, H.; Wu, J. Graphenelike Molecules with Four Zigzag Edges. Angew. Chem., Int. Ed. 2018, 57, 6541-6545.

(30) Newman, M. S. A New Synthesis of Coronene. J. Am. Chem. Soc. 1940, 62, 1683-1687.

(31) Craig, J. T.; Halton, B.; Lo, S. A new coronene synthesis. Aust. J. Chem. 1975, 28, 913.

(32) Shen, H. C.; Tang, J. M.; Chang, H. K.; Yang, C. W.; Liu, R. S. Short and efficient synthesis of coronene derivatives via rutheniumcatalyzed benzannulation protocol. J. Org. Chem. 2005, 70, 1011310116.

(33) van Dijk, J. T. M.; Hartwijk, A.; Bleeker, A. C.; Lugtenburg, J.; Cornelisse, J. Gram Scale Synthesis of Benzo[ghi]perylene and Coronene. J. Org. Chem. 1996, 61, 1136-1139.

(34) Scholl, R.; Meyer, K. Synthese desanti-diperi-Dibenz-coronens und dessen Abbau zum Coronen (Hexabenzo-benzol). (Mitbearbeitet von Horst v. Hoeßle und Solon Brissimdji). Ber. Dtsch. Chem. Ges. B 1932, 65, 902-915.

(35) Clar, E. Synthesis of Ovalene. Nature 1948, 161, 238-239.

(36) Rohr, U.; Schlichting, P.; Böhm, A.; Gross, M.; Meerholz, K.; Bräuchle, C.; Müllen, K. Liquid Crystalline Coronene Derivatives with Extraordinary Fluorescence Properties. Angew. Chem., Int. Ed. 1998, 37, $1434-1437$.

(37) Saidi-Besbes, S.; Grelet, E.; Bock, H. Soluble and liquidcrystalline ovalenes. Angew. Chem., Int. Ed. 2006, 45, 1783-1786.

(38) Li, J.; Chang, J.-J.; Tan, H. S.; Jiang, H.; Chen, X.; Chen, Z.; Zhang, J.; Wu, J. Disc-like 7, 14-dicyano-ovalene-3,4:10,11-bis(dicarboximide) as a solution-processible n-type semiconductor for air stable field-effect transistors. Chem. Sci. 2012, 3, 846-850.

(39) Broene, R. D.; Diederich, F. The synthesis of circumanthracene. Tetrahedron Lett. 1991, 32, 5227-5230.

(40) Dumslaff, T.; Yang, B.; Maghsoumi, A.; Velpula, G.; Mali, K. S.; Castiglioni, C.; De Feyter, S.; Tommasini, M.; Narita, A.; Feng, X.; Müllen, K. Adding Four Extra K-Regions to Hexa-peri-hexabenzocoronene. J. Am. Chem. Soc. 2016, 138, 4726-4729.

(41) Harvey, R. G.; Pataki, J.; Cortez, C.; Di Raddo, P.; Yang, C. X. A new general synthesis of polycyclic aromatic compounds based on enamine chemistry. J. Org. Chem. 1991, 56, 1210-1217.

(42) Lungerich, D.; Papaianina, O.; Feofanov, M.; Liu, J.; Devarajulu, M.; Troyanov, S. I.; Maier, S.; Amsharov, K. Dehydrative pi-extension to nanographenes with zig-zag edges. Nat. Commun. 2018, 9, 4756.

(43) Paterno, G. M.; Chen, Q.; Wang, X. Y.; Liu, J.; Motti, S. G.; Petrozza, A.; Feng, X.; Lanzani, G.; Müllen, K.; Narita, A.; Scotognella, F. Synthesis of Dibenzo[hi, st]ovalene and Its Amplified Spontaneous Emission in a Polystyrene Matrix. Angew. Chem., Int. Ed. 2017, 56, 6753-6757.

(44) Lutke Eversloh, C.; Avlasevich, Y.; Li, C.; Müllen, K. Palladiumcatalyzed pentannulation of polycyclic aromatic hydrocarbons. Chem. Eur. J. 2011, 17, 12756-12762.

(45) Mandal, A. B.; Lee, G.-H.; Liu, Y.-H.; Peng, S.-M.; Leung, M.-k. Formation of 4-Methylphenanthrenes in Palladium-Catalyzed Annulation of Diethyl 2,2'-Diiodo-4,4'-biphenyldicarboxylate with Internal Alkynes, Using Methyl Nitrobenzoates as the Methylating Agent. J. Org. Chem. 2000, 65, 332-336.

(46) Campo, M. A.; Huang, Q.; Yao, T.; Tian, Q.; Larock, R. C. 1,4palladium migration via $\mathrm{C}-\mathrm{H}$ activation, followed by arylation: synthesis of fused polycycles. J. Am. Chem. Soc. 2003, 125, 11506-11507.

(47) Ozaki, K.; Murai, K.; Matsuoka, W.; Kawasumi, K.; Ito, H.; Itami, K. One-Step Annulative pi-Extension of Alkynes with Dibenzosiloles or Dibenzogermoles by Palladium/o-chloranil Catalysis. Angew. Chem., Int. Ed. 2017, 56, 1361-1364. 
(48) Coles, D. M.; Chen, Q.; Flatten, L. C.; Smith, J. M.; Müllen, K.; Narita, A.; Lidzey, D. G. Strong Exciton-Photon Coupling in a Nanographene Filled Microcavity. Nano Lett. 2017, 17, 5521-5525.

(49) Chen, Q.; Wang, D.; Baumgarten, M.; Schollmeyer, D.; Müllen, K.; Narita, A. Regioselective Bromination and Functionalization of Dibenzo[hi,st] ovalene as Highly Luminescent Nanographene with Zigzag Edges. Chem. - Asian J. 2019, 14, 1703-1707.

(50) Chen, Q.; Thoms, S.; Stottinger, S.; Schollmeyer, D.; Mullen, K.; Narita, A.; Basche, T. Dibenzo[hist $]$ ovalene as Highly Luminescent Nanographene: Efficient Synthesis via Photochemical Cyclodehydroiodination, Optoelectronic Properties, and Single-Molecule Spectroscopy. J. Am. Chem. Soc. 2019, 141, 16439-16449.

(51) Fort, E. H.; Donovan, P. M.; Scott, L. T. Diels-Alder reactivity of polycyclic aromatic hydrocarbon bay regions: implications for metalfree growth of single-chirality carbon nanotubes. J. Am. Chem. Soc. 2009, 131, 16006-16007.

(52) Chen, Z.; Wannere, C. S.; Corminboeuf, C.; Puchta, R.; Schleyer, P. Nucleus-independent chemical shifts (NICS) as an aromaticity criterion. Chem. Rev. 2005, 105, 3842-3888.

(53) Schleyer, P. V. R.; Maerker, C.; Dransfeld, A.; Jiao, H.; van Eikema Hommes, N. J. R. Nucleus-Independent Chemical Shifts: A Simple and Efficient Aromaticity Probe. J. Am. Chem. Soc. 1996, 118, 6317-6318.

(54) Geuenich, D.; Hess, K.; Kohler, F.; Herges, R. Anisotropy of the induced current density (ACID), a general method to quantify and visualize electronic delocalization. Chem. Rev. 2005, 105, 3758-3772.

(55) Umezawa, Y.; Tsuboyama, S.; Takahashi, H.; Uzawa, J.; Nishio, $\mathrm{M}$. $\mathrm{CH} / \pi$ interaction in the conformation of organic compounds. A database study. Tetrahedron 1999, 55, 10047-10056.

(56) Sola, M. Forty years of Clar's aromatic pi-sextet rule. Front. Chem. 2013, 1, 22. 